\title{
RESVERATROL INCLUSION COMPLEX WITH $\beta$-CYCLODEXTRIN (RCD): CHARACTERIZATION AND EVALUATION OF TOXICITY IN WISTAR RATS
}

\author{
V. S. K. NISHIHIRA ${ }^{1}$, N. J. MEZZOMO ${ }^{2}$, M. D. BALDISSERA ${ }^{3}$, R. A. VAUCHER ${ }^{4}$, C. G. PINTO ${ }^{1}$, A. R. POHL ${ }^{1}$, P. GOMES ${ }^{1}$, \\ L. F. RODRIGUES JUNIOR ${ }^{5}$, C. P. FRIZZO' ${ }^{6}$, C. R. BENDER ${ }^{6}$, L. FANTINEL ${ }^{5}$, L. S. FERNANDES ${ }^{1}$, J. L. GIONGO ${ }^{7}$, \\ R. P. RAFFIN ${ }^{1}$, V. C. RECH ${ }^{1}$
}

${ }^{1}$ Laboratory of Nanotechnology, Post Graduate Program in Nanosciences, Franciscan University Center, Santa Maria, 97010-032, Rio Grande do Sul, Brazil, ${ }^{2}$ Laboratory of Experimental Neuropsychobiology, Federal University of Santa Maria (UFSM), Santa Maria, 97105-900, Rio Grande do Sul, Brazil, ${ }^{3}$ Microbiology and Parasitology Department, Health Sciences Center, Federal University of Santa Maria (UFSM), Santa Maria, 97105900, Rio Grande do Sul, Brazil, ${ }^{4}$ Post Graduate Program in Biochemistry and Bioprospecting, Center of Chemistry, Pharmaceutical and Food Science, Federal University of Pelotas (UFPel), Pelotas, 96010-900, Rio Grande do Sul, Brazil, ${ }^{5}$ Laboratory of Chemical Engineering, Franciscan University Center, Santa Maria, 97010-032, Rio Grande do Sul, Brazil, ${ }^{6}$ Nucleus of Chemistry of Heterocycles, Department of Chemistry, Federal University of Santa Maria (UFSM), Santa Maria, 97105-900, Rio Grande do Sul, Brazil, ' Laboratory of Pharmaceutical Technology, University of High Uruguay Regional Integrated (URI), Santiago, 97700-000, Rio Grande do Sul, Brazil

Email: vga.cielo@gmail.com

Received: 27 Sep 2016 Revised and Accepted: 12 Nov 2016

\section{ABSTRACT}

Objective: The aim of this study was to characterise the resveratrol inclusion complex with $\beta$-cyclodextrin (RCD) and evaluate their toxicity in wistar rats.

Methods: The RCD were prepared in ultra-turrax. For characterization of the RCD were used: Fourier transform infra-red Spectroscopy, Nuclear Magnetic Resonance (NMR), Differential Scanning Calorimetry (DSC) and X-ray powder diffraction. The RCD and others 4 treatments were performed by the chronic oral administration in 35 rats during $60 \mathrm{ds}$. After the treatments they were euthanized and the serum blood were collected to analyzed some hemogram and biochemical parameters including aspartyl aminotransferase (AST); alanine aminotransferase (AST); phosphatase alkaline (ALP); total bilirubin (TB); direct bilirubin (DB); total protein (TP); total cholesterol (TC), triacylglycerol (TAG), very low-density lipoprotein (VLDL), high-density lipoprotein (HDL), calcium, iron and phosphate using fully automated biochemistry analyzer.

Results: The characterization results indicated a successful formation of the RCD. All hematological parameters analysed were within the normal values in all the groups. Furthermore, the hemogram and biochemical parameters were significantly $(\mathrm{P}>0.05)$ similar to the control group.

Conclusion: The daily oral administration during $60 \mathrm{~d}$ of RCD are not harmful on blood parameters of Wistar rats. Thus, RCD can be used safely for treatment of some metabolic diseases.

Keywords: Resveratrol, $\beta$-cyclodextrin, Nanoscience, Hemogram, Biochemical and blood serum

(c) 2017 The Authors. Published by Innovare Academic Sciences Pvt Ltd. This is an open access article under the CC BY license (http://creativecommons.org/licenses/by/4. 0/) DOI: http://dx.doi.org/10.22159/ijpps.2017v9i1.15399

\section{INTRODUCTION}

Recent evidence has demonstrated that increased oxidative stress and decreased antioxidant protection are associated with various metabolic disorders [1,2]. Resveratrol (R) (3,5,4'-trihydroxystilbene) (fig. 1) is a phytoalexin present in a number of plant species [3]. Resveratrol has been extensively studied due to its antioxidant and anti-inflammatory properties, estrogenic effects, as well as the prevention and treatment of various metabolic disorders including, diabetes [4]. Resveratrol is easily absorbed in the gastrointestinal tract, metabolised and its excretion is very high, resulting in poor oral bioavailability [5]. Besides to being sensitive to external agents such as air, light and oxidative enzymes. This limitation could be overcome by the formation of inclusion complex (RCD) with cyclodextrin [6].

Cyclodextrins are nanoscale structures used in the development of drug delivery systems, to increase the solubility of hydrophobic substances in water further, protection against hydrolysis, oxidation, and photodecomposition, increasing stability and bioavailability [7].

Natural $\beta$-cyclodextrin is poorly water soluble whereas 2hydroxypropyl- $\beta$-cyclodextrin (CD) is widely used in the pharmaceutical field due to its modification of the physicochemical properties such as stability and solubility of the guest molecule [8-10].

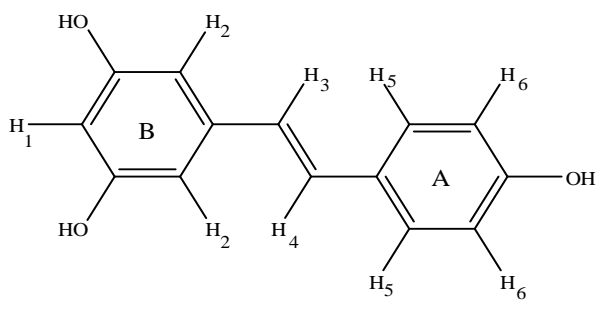

Fig. 1: Chemical structure of trans-R (own source)

However, it is important to explore the toxicity profile of RCD before to use as a therapeutic product in human disease. Despite its application, there are still many doubts about its toxicity in free or complex form to another compound. The aim of this study was to characterise the resveratrol inclusion complex with $\beta$-cyclodextrin (RCD) and evaluate their toxicity in Wistar rats.

\section{MATERIALS AND METHODS}

Materials

R, CD and HPLC grade ethanol were obtained from Sigma-Aldrich (USA) and J. T. Baker (USA), respectively. Water was purified by the Milli-Q ${ }^{\circledR}$ system. 


\section{Preparation of the inclusion complex}

The inclusion complexes were prepared using adapted method of Lu et al., [13]. Firstly was prepared $0.1 \mathrm{mmol}$ of CD solution in water (8 $\mathrm{ml}$ ) at $40{ }^{\circ} \mathrm{C}$ by continuous stirring in ultra-turrax (IKA ULTRATURRAX T18 digital, Germany) (3200 rpm) and an equimolar amount of $\mathrm{R}(0.1 \mathrm{mmol})$ was directly added to the suspension. $\mathrm{R}$ was previously suspended in ethanol $(2 \mathrm{ml})$. After stirring for one minute, the suspension was filtered through $0.45 \mu \mathrm{m}$ cellulose acetate membrane filter to removed undissolved particles [13]. The solvent was removed using rotary evaporation at $40{ }^{\circ} \mathrm{C}$ for about $10 \mathrm{~min}$ and the water was evaporated under vacuum for $8 \mathrm{~h}$. In all the processes were used aluminium foil to covert the flasks in order to minimise the photochemical degradation.

\section{Characterization of the inclusion complex}

Fourier transform infra-red spectroscopy analyses were performed previously in our laboratory [14]. Nuclear Magnetic Resonance (NMR) spectra were recorded on Bruker AVANCE 600. T1 and ${ }^{1} \mathrm{H}$ experiments were performed with samples diluted in $\mathrm{H}_{2} \mathrm{O}$ to evaluate the intermolecular interactions in the inclusion complex formation. Differential scanning calorimetry (DSC) experiments were performed using an MDSC Q2000 (T-zero ${ }^{\mathrm{TM}}$ DSC Technology, USA). The instrument was initially calibrated in standard MDSC mode using the extrapolated onset temperatures of melting indium $\left(156.60^{\circ} \mathrm{C}\right)$. The sample masses were weighed to an accuracy of \pm $0.001 \mathrm{mg}$ Dynamic light scattering measurements were performed at $298.15 \mathrm{~K}$ on a multiangle dynamic and static light scattering system (Brookhaven Instruments Corporation, NY, USA) with mini $\mathrm{L}-30$ laser $(35 \mathrm{~mW})$ variable operating at a fixed angle of $90^{\circ}$. In this study, the distributions of the relaxation times are shown as $\tau A(\tau)$ versus $\log \tau(\mu \mathrm{s})$. The hydrodynamic radius (Rh) of the aggregates was calculated using the stokes-Einstein relation [15]. Samples CD, R and RCD (1:1 ratio)-maintaining a final concentration of $50 \mathrm{mmol}$. The solvent mixture was previously filtered in a cellulose filter of $0.8 \mu \mathrm{m}$ pore size (MF-Millipore ${ }^{\mathrm{TM}}$, Ireland, UK). And finally, X-ray powder diffraction patterns were recorded on an X-ray diffractometer, Bruker D2 Advance, using $\mathrm{Cu}-\mathrm{K} \alpha(\lambda=1.5406 \AA)$ radiation, a $30 \mathrm{kV}$ voltage, and $10 \mathrm{~mA}$ current. The scanning rate employed was $0.03 \%$ s over the $2 \theta$ range of 5-60.

\section{Method validation}

The guidelines established by the Brazilian National Health Surveillance Agency (ANVISA). Regulation 899/200310 and International Conference of Harmonization (ICH) were employed for validation of the analytical method by UV-vis spectrophotometry [16].

\section{Standard and sample solution}

A standard stock solution of $400 \mu \mathrm{g} / \mathrm{ml}$ was prepared by weighing $10 \mathrm{mg}$ of $\mathrm{R}$ and dissolving it in a mixture of water and ethanol $(1: 1 \mathrm{v} / \mathrm{v})$. Sample preparation was also performed in the same way. From the stock, solution dilutions were prepared to achieve the required concentrations. The solutions used as the standard solution was magnetically stirred for $15 \mathrm{~min}$ at $40^{\circ} \mathrm{C}$.

\section{Development of the analytical method}

The proportions of ethanol and water were evaluated, in order to determine the best ratio of solvent to be used for development of the analytical method. For this, we took into consideration the solubility power of $\mathrm{R}$ and $\mathrm{CD}$, and the selectivity of $\mathrm{R}$ when associated with this solvent in relation to the wavelength value. The analysis of this solution was performed in a UV-vis spectrophotometer in the range of 200 to $400 \mathrm{~nm}$, to identify the wavelength of maximum absorption in the proportion chosen from ethanol and water. Subsequently, different techniques were performed to extract the complexed $\mathrm{R}$ using manual shaking, ultrasound, and magnetic stirring, varying the extraction time $(5,15$ and $30 \mathrm{~min})$. The temperatures $\left(40\right.$ and $\left.60^{\circ} \mathrm{C}\right)$ were also tested with magnetic stirring, varying the extraction time $(5,15$ and $30 \mathrm{~min})$.

\section{Specificity, linearity, precision, accuracy, and robustness}

Method specificity was assessed by comparing absorption spectra obtained in the region of 200 to $400 \mathrm{~nm}$, in a solution of $4 \mu \mathrm{g} / \mathrm{ml}: \mathrm{R}$, RCD, and CD. Linearity was evaluated by analysing a standard curve in a range of seven concentrations from 1 to $7 \mu \mathrm{g} / \mathrm{ml}$ for $\mathrm{R}$. Each concentration was performed in triplicate. The absorbance was measured at a wavelength of $306 \mathrm{~nm}$. The results were statistically analysed by analysis of variance (ANOVA), linear regression and Pearson correlation. Precision was evaluated by the same analyst repeating the procedure required for the analyses in a short period of time (repeatability) and intermediate precision, performed by another analyst on different days, but with the same equipment. The test consisted of samples: $3,4,5 \mu \mathrm{g} / \mathrm{ml}$ and the results were analysed using the relative standard deviation (RSD).

Accuracy was determined by the recovery assays of three standard concentrations, and the final concentration of the standard was: 3 , $3.5,4,4.5 \mu \mathrm{g} / \mathrm{ml}$. The result was expressed in percentage by the ratio of the average concentration determined experimentally and theoretical concentration corresponding to $50,75,100$ and $125 \%$ of $\mathrm{R}$ added to the samples. Accuracy was expressed as the ratio between the average concentration determined experimentally and theoretical concentration (ANVISA) [16]. To determine the robustness of the developed method we chose to use different times and temperature for the extraction of $\mathrm{R}$ from the inclusion complex. These studies were statistically analysed by ANOVA followed by Tukey test when the F value was significant.

\section{Animals}

Thirty-five male Wistar rats (two months old) with 200 to $250 \mathrm{~g}$ of weight were used in accordance with the Ethics Committee for Animal Research of the Franciscan University Center (protocol number 014/2012). The rats were kept in cages, four animals each, housed at a constant temperature and controlled humidity $\left(23 \pm 1^{\circ} \mathrm{C}\right.$; $70 \%$ respectively) on a light/dark cycle of $12 \mathrm{~h}$. They had free access to standard pellet and water. All chemicals were purchased from Sigma Chemical Co. (St. Louis, MO). The rats were randomly divided into five groups with seven rats in each group. The animals received daily, an oral dose of $0.02 \mathrm{ml} / \mathrm{g}$ rat for each treatment, as described. Groups: Control (C) received only water; Ethanol (E) received 2\% of ethanol solution body-weight-dependent (bwd) (ethanol was used to solubilize the R); Resveratrol (R) received $1 \mathrm{mg} / \mathrm{kg}$ bwd; Inclusion complex (RCD) treated with equivalent to $1 \mathrm{mg} \mathrm{R} / \mathrm{kg}$ bwd; CD (CD) treated with CD equivalent to inclusion complex, for $60 \mathrm{~d}$. After this, the rats were euthanised and their blood was collected into tubes with EDTA and without anticoagulant, to determine the hematological and biochemical parameters, respectively.

\section{Haematological analysis}

Whole blood parameters were evaluated using a T890 automatic cell counter (Beckman Coulter, USA). White blood cell (WBC), red blood cell (RBC) and platelet (PLT) were determined.

\section{Serum biochemistry}

The tubes without anticoagulant were centrifuged at $3000 \mathrm{rpm}$ for $15 \mathrm{~min}$ and the supernatant were collected. Serum levels of albumin, creatinine, urea, uric acid, total bilirubin (TB), direct bilirubin (DB), total protein (TP), total cholesterol (CT), calcium $(\mathrm{Ca})$, iron $(\mathrm{Fe})$, phosphate, high-density lipoprotein (HDL), very low-density lipoprotein (VLDL) and, triacylglycerol (TAG), aspartate aminotransferase (AST), alanine aminotransferase (ALT), alkaline phosphatase (ALP) were determined in an automated analyzer Vitros 250 (Ortho-Clinical Diagnostics, Rochester, NY), using Johnson and Johnson kits by chemical dried method.

\section{Statistical analysis}

Data were analysed by one-way ANOVA. When appropriate, was applied Tukey test. Values were considered significant when $\mathrm{p}<0.05$. Data are expressed as mean \pm standard deviation (SD). The data shown are from at least three independent experiments.

\section{RESULTS AND DISCUSSION}

\section{Characterization of the inclusion complex}

${ }^{1} \mathrm{H}$ NMR experiments are one of the most important tools to evidence the RCD formation when a molecule is incorporated into the CD cavity. Generally, the hydrogen atoms inside the cavity (H3 and H5) should be sensitive to the change of chemical environment, as previously reported by Ge et al., [17] (fig. 2). 

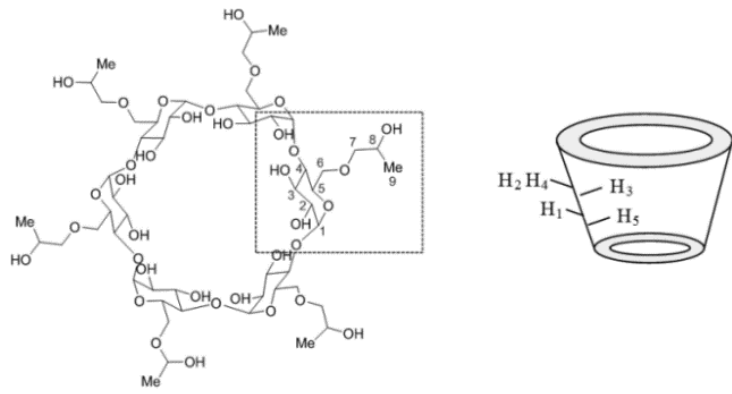

Fig. 2: Schematic representation of CD, spatial organization and numeration of atoms
The ${ }^{1} \mathrm{H}$ chemical shift variation $(\Delta \delta)$ between $\mathrm{CD}$ and RCD containing $\mathrm{R}$ is depicted in table 1. Comparison between ${ }^{1} \mathrm{H}$ NMR spectra of $\mathrm{CD}$ and RCD showed that the chemical shift of some nuclei changed when complex inclusion is formed.

In general, changes in chemical shift $\Delta(\delta)$ were small because the intermolecular interactions between the molecules are of noncovalent nature (e. g. Van der Waals forces, hydrogen bonds, hydrophobic interactions) [18].

It can be seen that the $\mathrm{H} 3$ shift to an up field while the $\mathrm{H} 5$ to downfield shift when the RCD is formed. ThA $\delta$ of the H3 and H5 were 0.025 and -0.069 , respectively, indicating that the $\mathrm{R}$ molecule enters the CD cavity, probably due to the occurrence of Van der Waals forces.

Table 1: ${ }^{1} \mathrm{H}$ NMR chemical shifts $(\delta)$ and chemical shift variation $(\Delta \delta)$ of $\mathrm{CD}$ hydrogens upon complexation with $\mathrm{R}$ in $\mathrm{D}_{2} \mathrm{O}$ at $25^{\circ} \mathrm{C}$

\begin{tabular}{lllllllll}
\hline CD & H1 & H2 & H3 & H4 & H5 & H6 & H7 & H9 \\
\hline$\Delta_{\mathrm{R}}$ & 5.080 & 3.655 & 4.021 & 3.600 & 3.732 & 3.872 & 3.506 & 1.157 \\
$\Delta_{\mathrm{RCD}}$ & 5.066 & 3.644 & 3.995 & 3.596 & 3.802 & 3.839 & 3.502 & 1.142 \\
$\Delta \delta$ & 0.014 & 0.010 & 0.025 & 0.003 & -0.069 & 0.033 & 0.004 & 0.015 \\
\hline
\end{tabular}

It is already established that the chemical environment changes have a direct effect on the hydrogen spirlattice relaxation times (T1) due to the alteration of the system of the molecular dynamics. Thus, the hydrogen spithattice relaxation times (T1) have been used to investigate supramolecular assemblies [19]. T1 experiments were performed to observe the occurrence of intermolecular interactions between $\mathrm{CD}$ and R in the RCD. The $\mathrm{H} 3$ of $\mathrm{CD}$ and $\mathrm{H} 4 / \mathrm{H} 4^{\prime}, \mathrm{H} 6$ and $\mathrm{H} 9 / \mathrm{H}^{\prime}$ of $\mathrm{R}$ were monitored in a $\mathrm{D}_{2} \mathrm{O} /$ methanol $(1: 1 ; \mathrm{v} / \mathrm{v})$ solution (for hydrogen numbers in chemical structure, see fig. 1 and fig. 2). T1 values of the free $C D$ and Rare longer than those of the same nucleus in the inclusion complex (table 2).

Table 2: Spin-lattice relaxation times (T1) at $25^{\circ} \mathrm{C}$ for R, CD and RCD in $\mathrm{D}_{2} \mathrm{O} /$ methanol-D4 solution (1:1; v/v)

\begin{tabular}{|c|c|c|c|}
\hline \multirow[t]{2}{*}{ Compounds } & \multicolumn{3}{|c|}{ T1 ${ }^{a}$ (s) } \\
\hline & $\mathrm{H}^{\mathrm{b}}$ & $\mathrm{H} 4 / \mathrm{H}^{\prime} \mathrm{\prime c}$ & H9/H9'c \\
\hline $\mathrm{R}$ & 1.626 & 1.770 & 1.364 \\
\hline $\mathrm{RCD}$ & 1.596 & 1.565 & 1.275 \\
\hline
\end{tabular}

Inclusion complex (RCD) and Resveratrol (R)

This result indicates the probable formation of RCD. In general, the $\mathrm{T} 1$ of the guest molecule (R) is known to decrease on complexation with $C D$ due to the increase in $\tau c$ with the increase of the apparent molecular weight. The signal assignment of $\mathrm{R}$ used in this work was based on spectral of $\mathrm{R}$ in $\mathrm{CDCl}_{3}[20]$.

Thermo analysis also has been applied to investigate the formation and thermal stability of RCD. The melting point and enthalpy of fusion of the RCD indicate changes in the intermolecular interactions and molecular arrangements in the lattice $[17,21]$. Data from the differential scanning calorimetry (DSC) and thermogravimetry (TGA) are given in table 3 .
Changes in the thermal profile of inclusion complex are observed in relation to $\mathrm{CD}$ and R. RCD shows only one phase transition (pt1) and it occurs at a temperature inferior to the corresponding phase transition of $\mathrm{CD}$ and R. However, this pt 1 is similar to pt 1 of $\mathrm{CD}$ and it can be related to the presence of water in the $\mathrm{CD}$, which is maintained after the RCD formation.

The presence of water in the CD (6.24\%) and in the RCD (5.82\%) was confirmed by TGA analysis. In addition, the melting point of the $\mathrm{R}\left(266^{\circ} \mathrm{C}\right)$ and of the $\mathrm{CD}\left(327^{\circ} \mathrm{C}\right)$ were not observed in the thermal profile of the RCD, as well as, the glass transition (Tg) observed in the $\mathrm{CD}$ at $245^{\circ} \mathrm{C}$ in the thermogram of CD.

Table 3: Thermal analysis obtained by DSC and TGA for CD, R and RCD

\begin{tabular}{|c|c|c|c|c|c|c|}
\hline Compound & $\mathrm{mp}_{1^{\mathrm{a}}}\left({ }^{\circ} \mathrm{C}\right)$ & $\begin{array}{l}\Delta H^{\circ}{ }_{\text {fus1 }}{ }^{b} \\
(\mathrm{~kJ} / \mathrm{g})\end{array}$ & $\mathrm{mp}_{2}{ }^{\mathrm{a}}\left({ }^{\circ} \mathrm{C}\right)$ & $\begin{array}{l}\Delta \mathbf{H}^{\circ}{ }_{\text {fus } 2}{ }^{b} \\
(\mathrm{~kJ} / \mathrm{g})\end{array}$ & $\mathrm{T}_{\mathrm{g}} \mathrm{c}\left({ }^{\circ} \mathrm{C}\right)$ & $\mathrm{T}_{\mathrm{d}}{ }^{\mathrm{d}}\left({ }^{\circ} \mathrm{C}\right)$ \\
\hline CD & $89 \pm 4$ & $205 \pm 25$ & $327 \pm 0$ & $321 \pm 35$ & $245 \pm 0$ & 353 \\
\hline $\mathrm{R}$ & $266 \pm 0$ & $264 \pm 35$ & - & - & - & 334 \\
\hline RCD & $83 \pm 4$ & $218 \pm 40$ & - & - & - & 356 \\
\hline
\end{tabular}

aMelting point. bMelting enthalpy. ${ }^{\mathrm{C}} \mathrm{Glass}$ transition. ${ }^{\mathrm{d} D e c o m p o s i t i o n}$ temperature determined at at $10{ }^{\circ} \mathrm{C} \mathrm{min}^{-1}$. Inclusion complex (RCD), HP- $\beta$-CD $(\mathrm{CD})$ and Resveratrol $(\mathrm{R})$. The experiments were performed in triplicate $(\mathrm{n}=3)$ and the expressed values as mean $\pm \mathrm{SD}$.

Decomposition temperature (Td) of the $\mathrm{CD}$ and R was 353 and 334 ${ }^{\circ} \mathrm{C}$ respectively. For $\mathrm{R}$ water was not observed. The RCD demonstrates a high thermal stability, and it is much greater than the separated compounds $\left(356^{\circ} \mathrm{C}\right)$.
Dynamic light scattering was used to evaluate the hydrodynamic radius $\left(R_{h}\right)$ of new $R C D$ formed by $C D$ and $R$ [22]. The size distribution of starting materials and inclusion complex are demonstrated in fig. 3. 


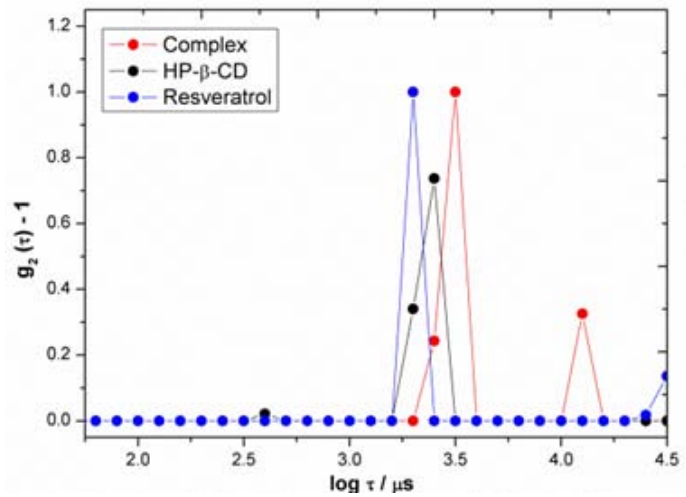

Fig. 3: Size distribution of inclusion complex (RCD), HP- $\beta$-CD (CD) and Resveratrol (R) in ethanol-water solution (1:1) at $25^{\circ} \mathrm{C}$

Based on these data, one relaxation mode $\left(\mathrm{Rh}_{1}\right)$ was detected for the separated compound (CD and R) and two for RCD $\left(\mathrm{Rh}_{1}\right.$ and $\left.\mathrm{Rh}_{2}\right)$. Population in the $\mathrm{R}_{\mathrm{h} 1}$ was monitored in order to analyse the formation inclusion complex in solution. The values are summarised in table 4.

Table 4: Hydrodynamic radius ( $R_{h 1}$ and $\left.R_{h 2}\right)$ of $C D, R$, and $R C D$ in an of ethanol-water solution $(1: 1)$ at $25^{\circ} \mathrm{C}$

\begin{tabular}{ll}
\hline Compound & $\left.\mathbf{R}_{\mathbf{h} 1}{ }^{\mathbf{a}} \mathbf{( n m}\right)$ \\
\hline CD & 232.23 \\
R & 199.52 \\
RCD & 301.03 \\
\hline
\end{tabular}

aHydrodynamic radius. Inclusion complex (RCD), HP- $\beta-\mathrm{CD}$ (CD) and Resveratrol (R)

From DLS, it was possible to observe that the RCD has $\mathrm{R}_{\mathrm{h} 1}$ greater than $\mathrm{R}_{\mathrm{h} 1}$ of $\mathrm{CD}$ and $\mathrm{R}$. This indicates a high probability of formation of a structure with a larger apparent molecular weight indicating a potential interaction between both components (mixture at 1:1 ratio). The $\mathrm{R}$ molecules can enter into the $\mathrm{CD}$ promoting an additional enlargement of this molecule. The $\mathrm{R}_{\mathrm{h} 2}$ of lower intensity of $\mathrm{CD} / \mathrm{R}$ mixture is related to particles of larger sizes and values in $\mathrm{nm}$ are outside the reliability limit of the technique.

X-ray powder diffraction patterns of pure R, CD, and RCD are shown in fig. 4. As shown in fig. $4 \mathrm{a}, \mathrm{R}$ has a crystalline structure and exhibits intense peaks between $5^{\circ}$ and $60^{\circ}$. The X-ray diffractogram of CD (fig. 4b) has no evident peaks, as expected for pure material. The inclusion complex (fig. 4c) shows a diffuse diffraction pattern, like $\mathrm{CD}$, with some less intense $\mathrm{R}$ peaks in $2 \theta=6.54^{\circ} ; 22.29^{\circ} ; 23.5^{\circ}$. $28.26^{\circ}$. This indicates that $\mathrm{R}$ in the complex mixture is less crystalline, implying the formation of a new structure.

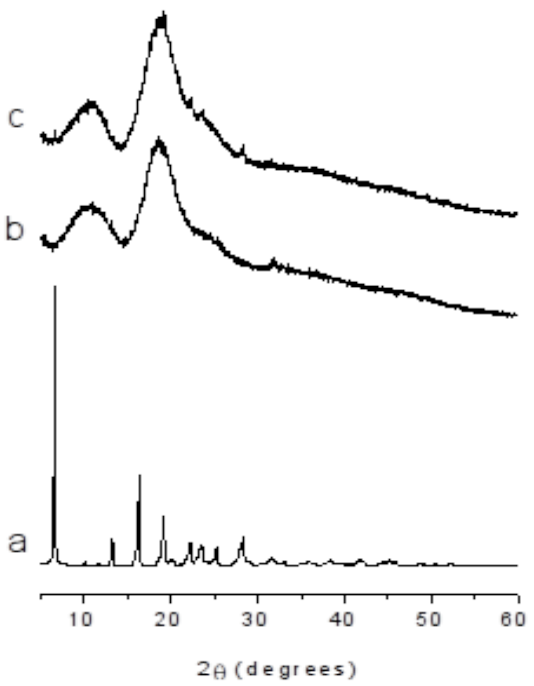

Fig. 4: X-ray powder diffractogram: (a) R, (b) CD, (c) RCD

\section{Method validation}

In order to observe the bigger wavelength of $\mathrm{R}$ absorption in the chosen solvent (a mixture of water and ethanol, 1:1, v/v) R solution was analysed at a concentration of $4 \mu \mathrm{g} / \mathrm{ml}$ to obtain a spectrum scan in the range of 200 to $400 \mathrm{~nm}$ [14]. The wavelength of maximum absorption of the chosen quantitative analysis was 306 $\mathrm{nm}$. Different conditions were tested for compounds to extract $\mathrm{R}$, such as agitation and ultrasound. When using the magnetic stirring, different temperatures $\left(40{ }^{\circ} \mathrm{C}\right.$ and $60^{\circ} \mathrm{C}$ ) and times ( $5 \mathrm{~min}, 15 \mathrm{~min}$, and $30 \mathrm{~min}$ ) were also used. The chosen condition was magnetic stirring for $15 \mathrm{~min}$ at $40^{\circ} \mathrm{C}$.

The different spectra scans demonstrated the specificity of this method and, for this test it can be seen that $\mathrm{CD}$ does not absorb in the wavelength region of $306 \mathrm{~nm}$. Therefore it will not interfere in the quantitative determination of the $R$, showing that the wavelength chosen will have specificity for this analysis and the determination method will be specific for R.

The results of linearity by ANOVA showed $\mathrm{P}<0.001$ indicating a significant $(\mathrm{p}<0.05)$ difference in readings between the concentrations analysed. From the slope of $0.1020 \pm 0.001253$ and intercept of $0.01543 \pm 0.005602$, the coefficient of linear correlation was calculated, thus obtaining the value of 0.9992 , these results being in accordance with current legislation (ANVISA) [16], which requires a minimum coefficient of 0.99 .

The precision of test results showed that the method presents good repeatability and reproducibility as internal data as showed in table 5. These results are in accordance with ANVISA [16], which requires a maximum of $5 \%$ RSD.

Table 5: Results of precision of RCD in intraday assay with two different analysts

\begin{tabular}{llll}
\hline Concentration $(\boldsymbol{\mu g} / \mathbf{m l})$ & D 1 $^{\boldsymbol{a}}$ Content $(\%)$ & D 2 $^{\boldsymbol{a}}$ Content $(\%)$ & D 3 $^{\boldsymbol{b}}$ Content $(\%)$ \\
\hline 3 & 105.54 & 106.67 & 100.10 \\
4 & 104.86 & 106.76 & 104.09 \\
5 & 100.62 & 104.27 & 103.35 \\
Mean & 103.67 & 105.90 & 102.52 \\
RSD & 2.57 & 1.33 & 2.07 \\
Internal reproducibility & & & \\
Mean (\%) & 104.03 & & \\
RSD & 1.65 & & \\
\hline
\end{tabular}

${ }^{a}$ Analyst $1 .{ }^{b}$ Analyst 2

The results obtained in the accuracy study demonstrated in the percentage of recoveries between $88-110 \%$ (table 6), which is in accordance with the
International Conference on Harmonization (ICH, 2005), which directs that the amount of recovered must be between $80-120 \%$. 
Table 6: Accuracy results of $R$ in RCD

\begin{tabular}{llll}
\hline Theorical concentration $(\boldsymbol{\mu g} / \mathbf{m l})$ & Experimental concentration $(\boldsymbol{\mu g} / \mathbf{m l})$ & Recovery $(\%)$ & 88.59 \\
\hline 3.00 & 2.83 & 9.95 & 97.93 \\
3.50 & 3.41 & 92.17 \\
4.00 & 3.79 & 2.42 & 109.94 \\
4.50 & 4.69 & 0.74 & \\
\hline
\end{tabular}

The robustness analysis of the analytical method by ANOVA and Tukey post-test of the data obtained during the development and validation of the analytical method showed that the time of magnetic stirring $(5,15$ and $30 \mathrm{~min})$ and temperatures of $40{ }^{\circ} \mathrm{C}$ and $60{ }^{\circ} \mathrm{C}$ for extraction of RCD did not affect the analysis. These conditions were necessary to extract the complexed $R$.

\section{Hematological and biochemical parameters}

Blood is the medium through which the body carries substances and the necessary elements for life and is formed by three types of cells: white blood cells (leukocytes), red cells (RBCs) or erythrocytes and platelets. Thus the changes in red blood cells are mainly related to the various types of existing anemias $[23,24]$. White blood cells are part of the immune system. This is a set of differentiated cells involved in the defence against pathogens and the monitoring and removal of non-self-antigens may be present or changed in the presence of local infections [25]. However, in this study, the effect of treatments on WBC, RBC and PLT did not show any significant differences ( $p>0.05$ ), when compared with the $C$ group (table 7).

Hepatic assessment has the answers to anatomical and biochemical changes in the liver [26]. Among the tests used for this evaluation can be included dosages of ALT, AST, ALP, albumin, TB, DB and PT are found abundantly in the liver, in moderate amounts in the kidney and in small amounts in the heart and skeletal muscles [27]. The plasma aminotransferases have been considered as sensitive indicators of hepatic damage since damaged liver cells release this enzyme into circulation, thus resulting in hepatic injury [28]. Its origin is predominantly in plasma, causing a rapid rise after liver injury [29]. The increased AST may be a sign of mitochondrial and cytoplasmic injury, although it is not a specific enzyme such as ALT to indicate hepatotoxicity [30]. Albumin is fully synthesised in the liver and contributes to maintaining the plasma osmolarity. It could represent an important protein reserve in addition to being a carrier of free fatty acids, amino acids, metals and bilirubin [31]. Bilirubin results from the breakdown of heme, which has poor solubility, besides being toxic. Therefore it is useful especially for diagnosis since the liver is responsible both for its conjugation with glucuronic acid, in this way increasing the solubility, and for its excretion [27]. The reduction in total protein is linked to liver failure, kidney and intestinal disorders, bleeding or deficiency in nutrition. Table 7 present those activities and concentrations in Wistar rat serum. This shows that the presence of R and RCD does not alter the activity of these important liver markers. Furthermore, the concentrations obtained are within the standard values for rats [32]. The same results on AST, ALT have been reported by Anthony et al., [33]. Moreover, the FAL level in our results showed a similar value exhibited by another research group [32]. Also, TB and TP in the study showed similar results found by Wolforf et al., [32].

Renal assessment is determined by measurement of urea, creatinine, and uric acid (table 7). The creatinine is produced endogenously, and it is released into body fluids at a constant rate, and its blood levels are maintained predominantly by glomerular filtration [34]. Thus, increased plasma creatinine indicates an impaired glomerular filtration or alterations in the flow of renal blood; however, a serious tubular dysfunction can also elevate the plasma creatinine [30]. Therefore, serum creatinine levels were used to analyse the effects of treatments on whole kidney function. Urea is produced by protein catabolism mainly of hepatic origin. The plasma urea levels could change by food intake and for the food protein content. Furthermore, plasma urea may be increased by the toxic effects of the renal tubules, cardiac injury, calculi or other obstructions [26]. Our results show normal levels of those parameters, similar concentrations to those found by Dantas et al., [35]. Furthermore, the concentrations obtained are within the standard values [36]. Moreover, our creatinine concentration was similar to that found by Wolforf et al., [32].

TC, TG, VLDL-c and HDL-c were used as biochemical markers to assess lipid profile (table 7). Changes in the metabolism of lipids, especially rising levels of cholesterol and TAG are associated with hypertension, obesity, and atherosclerosis that constitute risk factors for the increase in cardiovascular diseases and may lead to more serious consequences. High concentrations of HDL act as a protective factor, since they remove those lipids from the blood circulation $[37,38]$.

Table 7: Hematological and biochemical parameters after chronic exposure to RCD in wistar rats

\begin{tabular}{|c|c|c|c|c|c|}
\hline Parameters & $\mathbf{C}$ & $\mathbf{E}$ & $\mathbf{R}$ & RCD & CD \\
\hline WBC $\left(10^{3} \mathrm{~mm}^{-3}\right)$ & $5.5 \pm 0.3$ & $4.6 \pm 1.3$ & $6.2 \pm 0.4$ & $6.0 \pm 0.4$ & $4.8 \pm 0.4$ \\
\hline $\mathrm{RBC}\left(10^{6} \mathrm{~mm}^{-3}\right)$ & $8.1 \pm 0.8$ & $8.0 \pm 1.0$ & $7.7 \pm 0.4$ & $8.7 \pm 0.4$ & $8.6 \pm 0.4$ \\
\hline PLT $\left(10^{3} \mathrm{~mm}^{-3}\right)$ & $953 \pm 122$ & $885 \pm 138$ & $937 \pm 139$ & $853 \pm 122$ & $835 \pm 70$ \\
\hline AST (U/l) & $274 \pm 27$ & $306 \pm 21$ & $256 \pm 22$ & $294 \pm 54$ & $277 \pm 49$ \\
\hline $\operatorname{ALT}(U / \mathrm{l})$ & $59 \pm 8$ & $58 \pm 5$ & $51 \pm 4$ & $61 \pm 7$ & $53 \pm 3$ \\
\hline $\operatorname{ALP}(\mathrm{U} / \mathrm{l})$ & $119 \pm 23$ & $123 \pm 10$ & $144 \pm 19$ & $136 \pm 48$ & $129 \pm 16$ \\
\hline Albumin (mg/dl) & $2.5 \pm 0.4$ & $2.6 \pm 0.3$ & $2.6 \pm 0.3$ & $2.3 \pm 0.3$ & $2.4 \pm 0.2$ \\
\hline $\mathrm{TB}(\mathrm{mg} / \mathrm{dl})$ & $0.4 \pm 0.1$ & $0.4 \pm 0.05$ & $0.4 \pm 0.1$ & $0.3 \pm 0.1$ & $0.4 \pm 0.1$ \\
\hline $\mathrm{DB}(\mathrm{mg} / \mathrm{dl})$ & $0.1 \pm 0.1$ & $0.1 \pm 0.1$ & $0.1 \pm 0.1$ & $0.1 \pm 0.05$ & $0.1 \pm 0.1$ \\
\hline $\mathrm{TP}(\mathrm{mg} / \mathrm{dl})$ & $6.0 \pm 0.6$ & $6.1 \pm 0.3$ & $6.2 \pm 0.8$ & $5.7 \pm 0.9$ & $6.1 \pm 0.7$ \\
\hline Urea (mg/dl) & $38 \pm 6$ & $45 \pm 5$ & $47 \pm 3$ & $38 \pm 4$ & $41 \pm 1$ \\
\hline Creatinine (mg/dl) & $0.5 \pm 0.1$ & $0.4 \pm 0.1$ & $0.5 \pm 0.1$ & $0.5 \pm 0.1$ & $0.5 \pm 0.1$ \\
\hline Uric acid (mg/dl) & $1.5 \pm 0.1$ & $1.7 \pm 0.1$ & $1.4 \pm 0.1$ & $1.7 \pm 0.3$ & $1.8 \pm 0.4$ \\
\hline $\mathrm{TC}(\mathrm{mg} / \mathrm{dl})$ & $84 \pm 10$ & $92 \pm 9$ & $81 \pm 6$ & $76 \pm 17$ & $91 \pm 7$ \\
\hline TAG (mg/dl) & $61 \pm 9$ & $49 \pm 5$ & $63 \pm 6$ & $47 \pm 7$ & $49 \pm 10$ \\
\hline VLDL-c (mg/dl) & $12 \pm 2$ & $9 \pm 1$ & $13 \pm 1$ & $10 \pm 1$ & $10 \pm 2$ \\
\hline HDL-c (mg/dl) & $53 \pm 3$ & $52 \pm 4$ & $47 \pm 3$ & $47 \pm 8$ & $56 \pm 3$ \\
\hline Calcium (mg/dl) & $9.6 \pm 1.1$ & $9.6 \pm 0.6$ & $9.9 \pm 1.1$ & $9.1 \pm 1.1$ & $9.5 \pm 0.7$ \\
\hline Iron (mg/dl) & $213 \pm 21$ & $235 \pm 24$ & $234 \pm 32$ & $208 \pm 24$ & $244 \pm 36$ \\
\hline Phosphate (mg/dl) & $8.8 \pm 1.0$ & $9.5 \pm 1.1$ & $9.5 \pm 1.3$ & $8.7 \pm 0.9$ & $8.9 \pm 0.8$ \\
\hline
\end{tabular}

Data are expressed as mean \pm SD for 7 animals in each group. Abbreviations: WBC: white blood cell, RBC: red blood cell; PLT: platelets, AST: aspartate aminotransferase, AST: alanine aminotransferase, ALP: phosphatase alkaline, TB: total bilirubin, DB: direct bilirubin, TP: total protein, TC: Total cholesterol, TAG: Triacylglycerol, VLDL-c: very low-density lipoprotein-cholesterol and HDL-c: high-density-lipoprotein-cholesterol. Inclusion complex (RCD). The experiments were performed in triplicate $(n=3)$ and the expressed values as mean \pm SD. 
However, low values of TAG can be associated with the accumulation of fat in the liver [30]. The results of our study show that the treatments with RCD do not cause significant alteration ( $p>0.05)$ in the serum lipid profile of the experimental animals when compared with the control group. They show similar concentrations to those found by Dantas et al., [35]. Furthermore, the concentrations obtained are within the standard values [36].

Calcium metabolism is one of the more intensely controlled processes in the body. Although the serum calcium concentration corresponds to only $1 \%$ of total body calcium, this value is in a constant and fast exchange within the various calcium pools. Calcium plays an important role in a wide range of biologic functions, including intra- and extracellular signalling, cardiac and skeletal muscular contraction and relaxation, and neuromuscular impulse transmission $[30,39]$. The extracellular calcium intake (contribution) is closely linked to that of phosphate. Phosphorus, like calcium, plays several different roles in metabolic activities. Phosphorus does not exist in the free form but in the form of phosphates, this being present in the rich compounds energy (ATP, creatine, phosphate, etc.), activation of organic substances (glucose, amino acids, etc.) in nucleotide nucleic acids, phospholipids [30]. There is some relation between phosphate and calcium, maintaining with inversely proportional levels [40]. Iron is responsible for oxygen transport and storage, electron transport as well as being a component of several enzymes such as catalase and aconitase. It is an essential mineral in the formation of haemoglobin heme, being carried by a globulin called transferrin. The iron released from hemoglobin can be stored in the reticuloendothelial system in the form of ferritin and hemosiderin [27]. Moreover, increased levels of iron are associated with inflammatory actions involving granulocytes, and phagocytosis [41]. The results of serum electrolytes (calcium, iron, and phosphate) as reported in table 7 for all the experimental groups did not show significant $(p>0.05)$ change when compared with $C$ group. Furthermore, the serum concentrations of electrolytes are within the standard values [42].

\section{CONCLUSION}

In the present study, we showed the successful formation of RCD, confirmed by some characterization methods. Furthermore, hematological and biochemical parameters found to demonstrate that daily oral administration of R (1 mg/kg BW) and RCD in Wistar rats, during $60 \mathrm{~d}$, did not lead to hemotoxicity. These initial analyses allow us to infer that the use of $\mathrm{CD}$ in the inclusion complex has been proven safe for future applications, such as therapeutic treatment in some diseases.

\section{ACKNOWLEDGEMENT}

This work was supported by the research grants from Fundação de Amparo à Pesquisa do Estado do Rio Grande do Sul (FAPERGS), Coordenação de Aperfeiçoamento de Pessoal de Nível Superior (CAPES), Post Graduate Program in Nanosciences/Franciscan University Center and Conselho Nacional de Desenvolvimento Científico e Tecnológico (CNPq).

\section{CONFLICT OF INTERESTS}

The Author(s) declare(s) that they have no conflicts of interest to disclose.

\section{REFERENCES}

1. Styskal J, Van Remmen H, Richardson A, Salmon AB. Oxidative stress and diabetes: what can we learn about insulin resistance from antioxidant mutant mouse models? Free Radical Biol Med 2012;52:46-58.

2. Halliwell B. Free radicals and antioxidants: updating a personal view. Nutr Rev 2012;70:257-65.

3. Soleas GJ, Diamandis EP, Goldberg DM. Resveratrol: a molecule whose time has come? And gone? Clin Biochem 1997;30:91-113.

4. Lalitha V, Korah MC, Sengottuvel S, Sivakumar T. Antidiabetic and antioxidant activity of resveratrol and vitamin-c combination on streptozotocin are induced diabetic rats. Int J Pharm Pharm Sci 2015;7:455-8.

5. Boocock DJ. Phase I dose escalation pharmacokinetic study in healthy volunteers of resveratrol, a potential cancer chemopreventive agent. Cancer Epidemiol Biomarkers Prev 2007;16:1246-52.

6. Wenzel E, Somoza V. Metabolism and bioavailability of transresveratrol. Mol Nutr Food Res 2005;49:472-81.

7. Loftsson T, Duchene D. Cyclodextrins and their pharmaceutical applications. Int J Pharm 2007;329:1-11.

8. Latrofa A, Trapani G, Franco M, Serra M, Muggironi M, Fanizzi $\mathrm{FP}$, et al. Complexation of phenytoin with some hydrophilic cyclodextrins: Effect on aqueous solubility, dissolution rate and anticonvulsant activity in mice. Eur J Pharm 2001;52:65-73.

9. Mendhe AA, Kharwade RS, Mahajan UN. Dissolution enhancement of poorly water-soluble drug by cyclodextrins inclusion complexation. Int J Appl Pharm 2016;8:60-5.

10. Duchêne D, Wouessidjewe D, Ponchel GJ. Cyclodextrins and carrier systems. J Controlled Release 1999;62:263-8.

11. Rocha FRP, Teixeira LSG. Strategies to increase sensitivity in UV-VIS spectrophotometry. Quim Nova 2004;27:807-12.

12. Alves LDS, Rolim LA, Fontes DAF, Rolim-Neto PJ, Soares MFLaR, Sobrinho JLS. UV-Vis spectrophotometry analytical method development for quantifying efavirenz. Quim Nova 2010;33:1967-72.

13. Lu Z, Chen R, Liu H, Hu Y, Cheng B, Zou G. Study of the complexation of resveratrol with cyclodextrins by spectroscopy and molecular modeling. J Inclusion Phenom Macrocyclic Chem 2009;63:295-300.

14. Nishihira VSK, Fernandes LS, Mortari SR, Raffin RP, Rech VC. Characterization of Resveratrol/Hydroxipropyl- $\beta$-Cyclodextrin inclusion complex for subsequent application in hyperglycemic rats. Disciplinarum Scientia 2013;14:67-72.

15. Pecora R. Dynamic light scattering: applications of photon correlation spectroscopy, Springer Science and Business Media; 1985.

16. Brasil, Ministério da Saúde, Agência Nacional de Vigilância Sanitária (ANVISA); Resolução RE N 899, de 29/05/2003, Guia para validação de métodos analíticos e bioanalíticos; 2003.

17. Ge $\mathrm{X}$, He J, Qi F, Yang Y, Huang $\mathrm{Z}$, Lu R, Huang L. Inclusion complexation of chlorpropham with $\beta$-cyclodextrin: preparation, characterization and molecular modeling. Spectrochim Acta-Part A Mol Biomol Spectrosc 2011;81:397-403.

18. Yuan $\mathrm{C}$, Jin $\mathrm{Z}, \mathrm{Xu} \mathrm{X}$. Inclusion complex of astaxanthin with hydroxypropyl- $\beta$-cyclodextrin: UV, FTIR, $1 \mathrm{H}$ NMR and molecular modelling studies. Carbohydr Polym 2012;89:492-6.

19. Vold RL, Waugh JS, Klein MP, Phelps DE. Measurement of spin relaxation in complex systems. J Chem Phys 1968;48:3831-2.

20. Solladié G, Pasturel-Jacopé Y, Maignan J. A re-investigation of resveratrol synthesis by Perkins reaction. Application to the synthesis of aryl cinnamic acids. Tetrahedron 2003;59:3315-21.

21. Gindri IM. Preparation of TiO2 nanoparticles coated with ionic liquids: a supramolecular approach. ACS Appl Mater Interfaces 2014;6:11536-43.

22. Villetti MA. Static and dynamic light scattering of polyelectrolyte/surfactant solutions: the na-hyaluronate/ (C10TAB) system. Macromol Chem Phys 2004;205:907-17.

23. Agarwal N, Kumar VS, Gujjari SA. Effect of periodontal therapy on haemoglobin and erythrocyte levels in chronic generalised periodontitis patients: an interventional study. J Indian Soc Periodontol 2009;13:6-11.

24. Dallak M. Camel's milk protects against cadmium chlorideinduced hypochromic microcytic anemia and oxidative stress in red blood cells of white albino rats. Am J Pharmacol Toxicol 2009; 4:136-43.

25. Gkrania-Klotsas E, Ye Z, Cooper AJ, Sharp SJ, Luben R, Biggs ML, et al. Differential white blood cell counts and type 2 diabetes: systematic review and meta-analysis of cross-sectional and prospective studies. PLoS One 2010;5:e13405.

26. Yen MH, Weng TC, Liu SY, Chai CY, Lin CC. The hepatoprotective effect of bupleurumkaoi, an endemic plant to taiwan, against dimethylnitrosamine-induced hepatic fibrosis in rats. Biol Pharm Bull 2005;28:442-8.

27. Evans GO. Animal clinical chemistry: a primer for toxicologists. Taylor and Francis e-library; 2005.

28. Victoria FN, Anversa RG, Savegnago L, Lenardão EJ. Essential oils of E. uniflora leaves protect liver injury induced by acetaminophen. Food Biosci 2013;4:50-7. 
29. Bonora R, Ceriotti F, Férard G, Ferrero CA, Franck PF, Gella FJ, et al. Primary reference procedures for the measurement of catalytic activity concentrations of enzymes at 37 degrees C. International Federation of Clinical Chemistry and Laboratory Medicine. Part 6. Reference procedure for the measurement of catalytic concentration of gamma-glutamyl transferase. Clin Chem Lab Med 2002;40:734-8.

30. Evans GO. Animal clinical chemistry: a practical guide for toxicologists and biomedical researchers. Second edition; 2009.

31. Woodrow DA. Introduction to clinical Chemistry; 1987.

32. Wolford ST, Schroer RA, Gohs FX, Gallo PP, Brodeck M, Falk $\mathrm{HB}$, et al. Reference range database for serum chemistry and haematology values in laboratory animals. J Toxicol Envirom Health 1986;18:161-88.

33. Anthony OE, Ese AC, Lawrence EO. Regulated effects of capsicum frutescens supplemented diet (C. F. S. D) on fasting blood glucose level, biochemical parameters and body weight in alloxan are induced diabetic wistar rats. Br J Pharmacol 2013;3:496-507.

34. Burtis CA, Ashwood ER, Bruns DE. Tietz fundamentals of clinical chemistry. 6th edition. St Louis MO: Saunders/Elsevier; 2008.

35. Dantas JA, Ambiel CR, Cuman RKN, Baroni S, Amado CAB. Reference values of some physiological parameters in the rats of the central biotery at the state university of maringá, State of Paraná. Acta Sci Health Sci 2006;28:165-70.
36. Lima CM, Lima AK, Melo MGD, Dória GAA, Leite BLS, Serafini $\mathrm{MR}$, et al. Valores de referência hematológicos e bioquímicos de ratos (Rattus novergicus linhagem Wistar) provenientes do biotério da UniversidadeTiradentes. Sci Plena 2014;10:034601.

37. Baynes JW, Dominiczack MH. Bioquímica médica. 2ed. Rio de Janeiro, Elsevier; 2007. p. 716.

38. Devlin TM. Manual de bioquímica: com correlações clínicas. São Paulo: E. Blucher; 2007. p. 1186

39. Peacock M. Calcium metabolism in health and disease. Clin J Am Soc Nephrol 2010;5:S23-30.

40. Cisternas JR, Vargas J, Monte O. Fundamentos de bioquímica experimental. 2. ed. São Paulo, Editora Atheneu; 2001. p. 242.

41. Evans GO. Animal hematotoxicology: a practical guide for toxicologists and Biomedical Researchers. CRC Press; 2008.

42. Giknis MLA, Clifford CB. Clinical laboratory parameters Crl: Wl (Han) Rats. Charles River Laboratories; 2008.

\section{How to cite this article}

- Vivian Shinobu Kishimoto Nishihira, Nathana Jamille Mezzomo, Matheus Dallaméa Baldissera, Rodrigo De Almeida Vaucher, Cláudia Grigolo Pinto, Ariane Ribas Pohl, Patricia Gomes, Luiz Fernando Rodrigues Junior, Clarissa Piccinin Frizzo, Caroline Raquel Bender, Leonardo Fantinel, Liana da Silva Fernandes, Janice Luehring Giongo, Renata Platcheck Raffin, Virginia Cielo Rech. Resveratrol inclusion complex with $\beta$-cyclodextrin (RCD): characterization and evaluation of toxicity in Wistar rats. Int J Pharm Pharm Sci 2017;9(1):27-33. 